JURNAL ILMIAH KEBIDANAN IMELDA

Vol.6, No.2, September 2020, pp. 84-87

ISSN: 2597-7180 (Online),2442-8116 (Print)

\title{
HUBUNGAN TINGKAT PENGETAHUAN IBU NIFAS TENTANG GIZI IBU SELAMA HAMIL DENGAN BERAT BAYI LAHIR NORMAL DI RSUD ARIFIN ACHMAD
}

\author{
Fatma Richa Rahmana ${ }^{1}$, Mira Yani ${ }^{2}$
}

STIKes Pekanbaru Medical Center, Indonesia

\begin{tabular}{l} 
Article Info \\
\hline Article history: \\
Received Sep 9, 2019 \\
Revised Sep 23, 2020 \\
Accepted Sep 25, 2020 \\
\hline
\end{tabular}

\section{Keywords:}

Knowledge

Postpartum mothers

Nutrition for pregnant

\begin{abstract}
Mother's knowledge has a significant effect on birth weight. With sufficient nutritional knowledge, it is hoped that someone can change behavior for the better condition, so that mothers can choose nutritious food ingredients and compile a balanced menu according to their needs and tastes. Therefore, through good knowledge about nutrition during pregnancy, it is hoped that mothers can plan programs healthy pregnancy, and will give birth to a baby with normal weight ( $\geq 2500$ grams). The purpose of this study was to determine the relationship between the level of knowledge of post-partum mothers about maternal nutrition during pregnancy with the weight of the baby she was born with. This research is an analytical study with a cross sectional research design. The technique used in sampling is accidental sampling with a total sample of 32 postpartum mothers in Camar I Room Arifin Achmad Hospital, Riau Province, the tools used in sampling are questionnaires, and analyzed by univariate and bivariate using the chi square statistical test formula. The results of the univariate analysis were 23 people (71.9\%) mothers who had high knowledge of pregnant women nutrition, and 27 people (84.3\%) mothers who had babies with normal birth weight $(\geq 2500$ grams). From the results of the calculation of the chi square statistical test, it is obtained $x^{2}$ count 5.1 and $x^{2}$ table 2.70. Furthermore, it is compared between calculated $x^{2}$ and $x^{2}$ table, namely 5.1>2.70. So the results of the chi square statistical test showed that there was a significant relationship between the mother's knowledge of nutrition during pregnancy and the birth weight of the baby. Suggestions are given to related parties, in this case the hospital, to continuously strive to increase maternal knowledge about health in general and maternal nutrition during pregnancy, especially through health promotion efforts.
\end{abstract}

This is an open access article under the CC BY-SAlicense.

This is an open access article under the CC BY-SAlicense.
Corresponding Author:
Fatma Richa Rahmana,
Program Studi D-III Kebidanan,
STIKes Pekanbaru Medical Center,
J1. Lembaga Pemasyarakatan No. 25 Gobah, Kec. Sail Kota Pekanbaru, Riau - Sumatera Utara.
Email: fatmaricharahmana@gmail.com

\section{INTRODUCTION}

Kehamilan merupakan sebuah anugerah, diperlukan perhatian ekstra selama masa kehamilan, kelahiran, serta pasca kelahiran untuk memastikan proses tumbuh kembang yang optimal bagi sang buah hati. Selayaknya, kehamilan yang terjadi adalah kehamilan yang aman dan berkualitas. Aman dalam arti terhindar 
dari komplikasi yang mungkin terjadi selama kehamilan. Berkualitas dalam arti ibu dan bayi tetap dalam keadaan yang sehat (Depkes RI, 2010).

Masa kehamilan itu memerlukan tambahan gizi yang sangat banyak, ibu juga memerlukan tambahan gizi yang lebih besar lagi menjelang kelahiran dan menyusui. Seorang ibu hamil yang mengalami kekurangan gizi, maka bayi yang dilahirkan akan mengalami berat badan yang rendah, mungkin sakit-sakitan, dan mempengaruhi kecerdasannya (Atikah, 2009). Kekurangan gizi selama masa kehamilan maka bayi yang di kandungnya akan menderita kekurangan gizi. Apabila hal ini berlangsung terus-menerus dan tidak segera di atasi maka bayi akan lahir dengan BBLR (di bawah 2500 gram) (Atikah, 2009).

Kondisi BBLR akan sangat berpengaruh terhadap perkembangan kesehatan anak selanjutnya. Selain kekurangan gizi, bayi yang baru lahir tersebut juga akan mengelami kemunduran perkembangan otak. Hal ini akan berakibat terjadinya penurunan kemampuan belajar dan kemampuan akademik pada usia yang lebih lanjut. Selain itu bayi BBLR mempunyai kemungkinan meninggal sebelum usia satu tahun, 17 kali lebih besar dibandingkan dengan anak yang dilahirkan dengan berat badan normal (Siti, 2010).

Disamping itu tingkat pendidikan juga mempunyai hubungan yang eksponensial dengan tingkat kesehatan. Semakin tinggi tingkat pendidikan semakin mudah menerima konsep hidup sehat secara mandiri, kreatif dan berkesinambungan. Latar belakang pendidikan seseorang berhubungan dengan pengetahuan, jika pengetahuan gizi ibu baik maka diharapkan status gizi ibu dan balitanya juga baik, sebab dari gangguan gizi adalah kurangnya pengetahuan tentang gizi atau kemampuan meningkatkan pengetahuan tentang gizi (Suhardjo, 2008).

Tingkat pendidikan sangat mempengaruhi kemampuan penerimaan informasi gizi. Masyarakat dengan tingkat pendidikan yang rendah akan senantiasa mempertahankan tradisi - tradisi yang salah yang berhubungan dengan makanan, sehingga sulit menerima informasi baru dibidang gizi (Suhardjo, 2008). Tingkat pendidikan ikut menentukan atau mempengaruhi mudah tidaknya seseorang menerima suatu pengetahuan, semakin tinggi pendidikan maka seseorang akan lebih mudah menerima informasi-informasi gizi. Melalui pengetahuan gizi yang dimiliki ibu, diharapkan tercipta pola kebiasaan makan yang baik dan sehat, sehingga dapat mengetahui kandungan gizi, sanitasi dan pengetahuan yang terkait dengan pola makan lainnya (Handayani, 2004).

Kurangnya pengetahuan dan salah konsepsi tentang kebutuhan pangan dan nilai pangan adalah umum dijumpai setiap negara di dunia. Kemiskinan dan kekurangan persediaan pangan yang bergizi merupakan faktor penting dalam masalah kurang gizi, sebab yang penting dari gangguan gizi adalah kekurangan pengetahuan tentang gizi atau kemampuan untuk menerapkan informasi tersebut dalam kehidupan sehari-hari (Suhardjo, 2008).

Dengan pengetahuan gizi yang cukup diharapkan seseorang dapat mengubah perilaku ke arah yang lebih baik, sehingga dapat memilih bahan makanan bergizi serta menyusun menu seimbang sesuai dengan kebutuhan dan selera serta akan mengetahui akibat adanya kurang gizi. Pemberian pengetahuan gizi yang baik diharapkan dapat mengubah kebiasaan makan yang semula kurang baik menjadi lebih baik (Depkes RI, 2007). Berdasarkan latar belakang di atas, maka penulis tertarik untuk mengangkat judul "Hubungan Tingkat Pengetahuan Ibu Nifas tentang Gizi Ibu Selama Hamil dengan Berat Bayi Lahir Normal di RSUD Arifin Achmad".

\section{RESEARCH METHOD}

Penelitian ini termasuk penelitian analitik dengan menggunakan analisis univariat dan bivariat yaitu sesuai dengan rumus uji statistik chi square untuk menghubungkan variabel bebas dengan variabel terikat melalui pengukuran pada waktu bersamaan dengan tujuan untuk melihat variabel bebas (independent) dan variabel terikat (dependent) yang dilakukan pada saat pengolahan data. Penelitian ini telah dilakukan di Ruang Camar 1 RSUD Arifin Achmad Pekanbaru. Populasi adalah keseluruhan objek penelitian atau objek yang akan diteliti (Notoatmodjo, 2010:115). Populasi dalam penelitian ini berjumlah 809 orang ibu nifas. Teknik Pengambilan sampel yang digunakan Accidental sampling, dengan Jumlah sampel sebanyak 32 orang responden.

\section{RESULTS AND ANALYSIS}

3.1 Hasil

A. Analisa Univariat

Responden Penelitian ini adalah ibu nifas yang melahirkan di RSUD Arifin Achmad dan dirawat di ruang camar RSUD Arifin Achmad. Penelitian ini dilakukan selama tiga minggu. 


\section{Karakteristik Responden}

Tabel 1. Distribusi Frekuensi Karakteristik Responden Menurut Umur di Ruang Camar I RSUD Arifin Achmad

\begin{tabular}{lcc}
\hline \multicolumn{1}{c}{ Karakteristik } & Frekuensi (n) & Persentase (\%) \\
\hline Umur Responden & & \\
\hline $20-25$ thn & 9 & $28,1 \%$ \\
\hline $26-30$ thn & 11 & $34,4 \%$ \\
\hline $31-35$ thn & 8 & $25 \%$ \\
\hline$>35$ tahun & 4 & $12,5 \%$ \\
\hline Jumlah & $\mathbf{3 2}$ & $\mathbf{1 0 0 \%}$ \\
\hline & Sumber: Analisis Data Primer
\end{tabular}

Tabel 2. Distribusi Frekuensi Karakteristik Responden Menurut Tingkat Pendidikan di Ruang Camar I RSUD Arifin Achmad

\begin{tabular}{lcc}
\hline Karakteristik & Frekuensi (n) & Persentase (\%) \\
\hline Pendidikan Responden & & \\
\hline Rendah (SD -SMP) & 22 & $68,7 \%$ \\
\hline Sedang (SMA) & 8 & $25 \%$ \\
\hline Tinggi (PT) & 2 & $6,25 \%$ \\
\hline Jumlah & $\mathbf{3 2}$ & $\mathbf{1 0 0 \%}$ \\
\hline
\end{tabular}

Sumber: Analisis Data Primer

Tabel 3. Distribusi Frekuensi Karakteristik Responden Menurut Sumber Informasi yang Diterima di Ruang Camar I RSUD Arifin Achmad

\begin{tabular}{lcc}
\hline Karakteristik & Frekuensi (n) & Persentase (\%) \\
\hline Sumber informasi & & \\
\hline Buku/majalah/Koran & 21 & $75 \%$ \\
\hline Televisi / radio & 6 & $21,4 \%$ \\
\hline Internet & 1 & $3,5 \%$ \\
\hline Jumlah & $\mathbf{2 8}$ & $\mathbf{1 0 0 \%}$ \\
\hline & Sumber: Analisis Data Primer
\end{tabular}

Tabel 4. Distribusi Frekuensi Tingkat Pengetahuan Ibu tentang Gizi Ibu Selama Hamil di Ruang Camar I

\begin{tabular}{lcc}
\multicolumn{3}{c}{ RSUD Arifin Ahcmad } \\
\hline Tingkat Pengetahuan & Frekuensi (n) & Persentase (\%) \\
\hline Tinggi & 23 & $71,9 \%$ \\
\hline Rendah & 9 & $28,1 \%$ \\
\hline Jumlah & $\mathbf{3 2}$ & $\mathbf{1 0 0 \%}$ \\
\hline \multicolumn{4}{c}{ Sumber: Analisis Data Primer }
\end{tabular}

Dari tabel 4 di atas terdapat 23 orang $(71,9 \%)$ ibu-ibu yang mempunyai pengetahuan tinggi tentang gizi ibu hamil dan $9(28,1 \%)$ orang yang pengetahuan nya rendah.

Tabel 5. Distribusi Frekuensi Berat Badan Bayi yang Dilahirkan Ibudi Ruang Camar I RSUD Arifin Achmad

\begin{tabular}{lcc}
\hline Berat Bayi Lahir & Frekuensi (n) & Persentase (\%) \\
\hline$\geq 2500$ gram & 27 & $84,3 \%$ \\
\hline$<2500$ gram & 5 & $15,6 \%$ \\
\hline Jumlah & $\mathbf{3 2}$ & $\mathbf{1 0 0 \%}$ \\
\hline
\end{tabular}

Sumber: Analisis Data Primer

Dari tabel 5 di atas dapat dilihat bahwa 27 orang $(84,4 \%)$ ibu-ibu mempunyai bayi dengan berat lahir normal ( $\geq 2500$ gram) dan 5 orang $(15,6 \%)$ ibu-ibu mempunyai bayi dengan berat lahir rendah.

Tabel 6. Hubungan Tingkat Pengetahuan Ibu Nifas tentang Gizi Ibu Selama Hamil dengan Berat Bayi Lahir Normal di Ruang Camar I RSUD Arifin Achmad

\begin{tabular}{|c|c|c|c|c|c|c|}
\hline \multirow[t]{3}{*}{ Pengetahuan } & \multicolumn{4}{|c|}{ Berat BayiLahir } & \multirow{2}{*}{\multicolumn{2}{|c|}{ Total }} \\
\hline & \multicolumn{2}{|c|}{$\geq 2500$ gram } & \multicolumn{2}{|c|}{$<2500$ gram } & & \\
\hline & (n) & $(\%)$ & (n) & $(\%)$ & (n) & $(\%)$ \\
\hline Tinggi & 22 & $68,7 \%$ & 1 & $3,1 \%$ & 23 & $71,9 \%$ \\
\hline Rendah & 5 & $15,6 \%$ & 4 & $12,5 \%$ & 9 & $28,1 \%$ \\
\hline Jumlah & 27 & $84,3 \%$ & 5 & $15,6 \%$ & 32 & $100 \%$ \\
\hline
\end{tabular}

Sumber: Analisis Data Primer 


\subsection{Pembahasan}

B. Analisa Bivariat

Hasil uji statistik antara pengetahuan tentang gizi ibu selama hamil dengan berat bayi lahir normal pada ibu nifas di Ruang Camar I RSUD Arifin Achmad Provinsi Riau adalah Ha diterima, dimana $x^{2}$ hitung $>$ $\mathrm{X}^{2}$ tabel yaitu 5,1>2,70. Sehingga dapat disimpulkan bahwa adanya hubungan yang bermakna antara pengetahuan tentang gizi ibu hamil dengan berat badan bayi baru lahir. Dengan pengetahuan gizi yang cukup diharapkan seseorang dapat mengubah perilaku ke arah yang lebih baik, sehingga dapat memilih bahan makanan bergizi serta menyusun menu seimbang sesuai dengan kebutuhan dan selera serta akan mengetahui akibat adanya kurang gizi. Pemberian pengetahuan gizi yang baik diharapkan dapat mengubah kebiasaan makan yang semula kurang baik menjadi lebih baik.

\section{CONCLUSION}

Berdasarkan Landasan teori dan didukung oleh analisa dan hasil uji, maka dapat disimpulkan bahwa terdapat hubungan yang bermakna antara pengetahuan tentang gizi ibu hamil dengan berat badan bayi baru lahir.

\section{REFERENCES}

Arisman. 2014. Gizi Dalam Daur Kehidupan. Jakarta: EGC.

Depkes RI. 2005. Rencana Pembangunan Kesehatan Menuju Kesehatan Indonesia Sehat 2010. Jakarta: Depkes RI.

Depkes RI. 2007. Penatalaksanaan Menu Seimbang Pada Ibu Hamil. http/www.depkes.go.id. Jakarta: Depkes RI.

Handayani, Sri. 2004. Pangan Dan Gizi. Jakarta: University Press.

Hidayat, A. Aziz Alimul. 2011. Metodologi Penelitian Kebidanan Dan Teknik Analisis Data. Surabaya: Salemba Medika.

Kusmiyati, dkk. 2009. Perawatan Ibu Hamil. Yogyakarta: Fitramaya.

Miyata, Ibrahim., Misaroh, Siti., Proverawati, Atikah. 2010. Nutrisi Janin Dan Ibu Hamil. Yogyakarta: Nuha Medika.

Nadesul, Handrawan. 2008. Makanan Sehat Untuk Ibu Hamil. Jakarta: Puspa Swara.

Nanny, Vivian. 2011. Asuhan Neonates Bayi Dan Anak Balita. Jakarta: Salemba Medika.

Notoatmodjo, Soekidjo. 2010. Metodologi Penelitian Kesehatan. Jakarta: Rineka Cipta.

Novaria. 2000. Pengetahuan Dan Pendidikan Seputar Kehamilan. Jakarta: Puspa Swara.

Proverawati, Atikah., Asfuah, Siti. 2009. Gizi Untuk Kebidanan. Yogyakarta: Nuha Medika.

Santjaka, Aris. 2011. Statistik Untuk Penelitian Kesehatan. Yogyakarta: Nuha Medika.

Suhardjo. 2008. Perencanaan Pangan Dan Gizi. Jakarta: Bumi Aksara.

\section{BIOGRAPHIES OF AUTHORS}

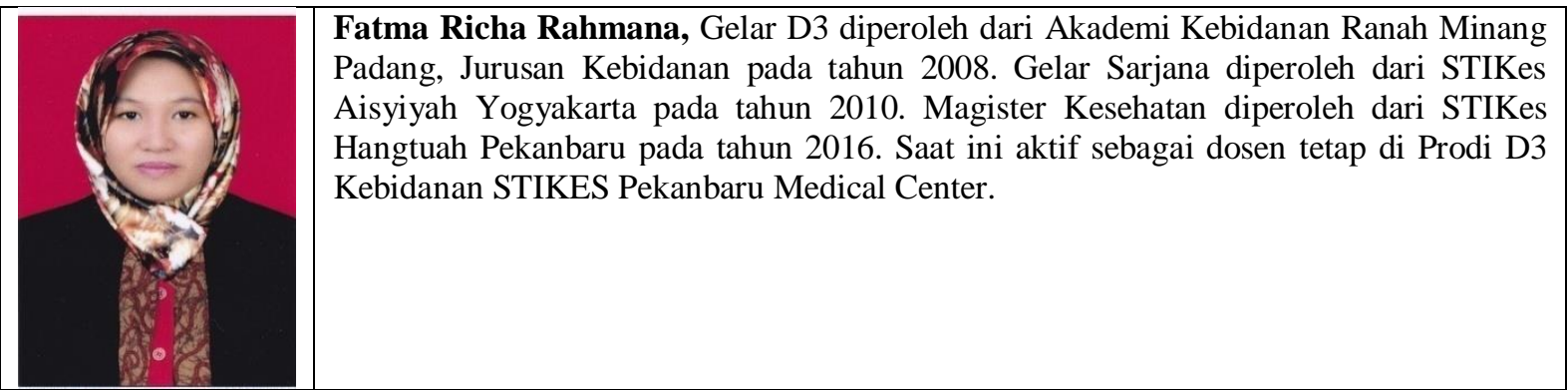

